\title{
Reflexões sobre a educação de profissionais da área de saúde
}

\author{
Reflections on the education of health professionals
}

Fátima $\mathrm{M}$ aria $\mathrm{N}$ amen ${ }^{1}$ João Galan J r. ${ }^{1}$
${ }^{1}$ Departamento de Psiquiatria e Saúde M ental, FaculdadedeM edicina,

UniversidadeFederal Fluminense. Rua M arquês do Paranás/n, H ospital

Universitário Antônio

Pedro, Centro. 24020-006

Niterói RJ.

fmariacn@gmail.com

${ }^{2}$ Departamento de $M$ ateriais

Dentários, Faculdadede

Odontologia, Universidade

Estadual do Rio deJaneiro.
Abstract The objective of the present article is primordially to rise controversies about the education as a whole and the scientific knowledge as important foundations in the academic formation. Believing that the incessant search of the masters degree courses should not limit to the the ories as a mere academic education. Themethodological dynamics of the knowledge is questioned, as well as truth and knowledge. The human condition isintroduced as a theme that has a tendency to the post-modern era, discussing the liquidity and human fragileness. The complexity and interdisciplinarity were questioned. The approach of the qualitative research was correlated to the human and existential issue. Besides other topics regarding education and research such as bioethics, viability of the uninterested research, mass production and theories well addressed, we aimed at showing that the education process and knowledge can create events so that the student becomes the subject, an individual with self-criticism and with dialectics posture.

Key words Education, Health, Knowledge
Resumo 0 objetivo do presente ensai o é o levantamento de polêmicas sobre a educação como um todo e o conhecimento científico como alicerces importantes na formação acadêmica. Acreditando quea busca incessantedos cursos depós-graduação não se deveria restringir às teses como mera formalização, questiona-se a dinâmica metodológica do conhecimento, bem como verdade e saber. A condição humana é introduzida como um tema que faz um viés com a era dita pós-moderna, discutindo a liquidez eefemeridades humanas. A complexidade e interdisciplinaridade foram questionadas como um novo formato detrabal ho. A abordagem da pesquisa qual itativa correlaciona-se com a questão humana e existencial. Além de outros tópicos a respeito de educação e pesqui sa tais como bioética, viabilidade da pesquisa desinteressada, produção massificante e teses bem direcionadas, quisemos mostrar o quanto o processo de educação e conhecimento podem formar eventos para que 0 aluno se torne sujeito, um indivíduo com autocrítica e com postura dialética.

Palavras-chave Educação, Saúde, Conhecimento 
A ciência não énem pecado, nem fatalidade. $\mathrm{N}$ em nossa filha, mas nossa invenção; a ciência como disciplina nunca crescerá a ponto de pensar por si mesma e assumir sua responsabilidade. Somente os indivíduos podem fazer tais coisas.

Shattuck

\section{Introdução}

A educação ea metodologia científica são alicerces para um curso de pós-graduação. No entanto, parece existir um débito em toda pós-graduação brasileira em relação a esses dois pilares. Segundo Demo ${ }^{1}$,"o conhecimento científico, que foi inventado para dizermos o que é objetivamente certo, anda muito incerto diante das discussões ditas pós-modernas".

Para realizar qualquer argumentação, apelamos para afirmações ainda não argumentadas, porque éimpraticável partir de fundo sem achar 0 alicerce. Muitas das argumentações disponíveis são incorporadas em nosso discurso sem questionamento. Evidentemente, se fossemos questionar tudo, não sairíamos da primeira sentença, mas pode ter a vantagem, questionando os conceitos básicos, de perceber criticamente 0 queainda não foi questionado. N esse sentido que muitos diriam hoje, sobretudo, queo caráter científico do discurso está menos nas pretensas comprovações do quena convivência criativa ecrítica com a dúvida ${ }^{1}$.

I sso nos leva a desconstruir dois temas: educação e metodologia científica e todos os seus desdobramentos dentro de um microcosmo, muito particular, quando se trata de cursos na área de saúdeeinterdisciplinar. Talvez não setrate de aventar propriamente de crise do conhecimento, porque esse tipo de crise - a capacidade dequestionar e, sobretudo, de sequestionar - éa razão de ser mais profunda da ciência'. Que as teorias se tornem obsoletas é o que há de mais natural, dentro do processo dinâmico intrinsecamente dialético. Nesse sentido, o advento do pós - modernismo é menos crise, do que vitalidade. Deveria preocupar-nos muito mais a calmaria, como sucede em muitos ambientes acadêmicos, onde ninguém questiona ninguém, ficando tudo sempre como está. É sinal de que o conhecimento não está sendo reconstruído pela via do questionamento sistemático. Se olharmos bem a dialética questionadora do conhecimento, temos deaceitar que conhecimento crítico ésem- pre, pelo menos em algum sentido, novo, já que o questionamento acrescenta-Iheal guma dimensão, algum olhar, alguma preocupação que antes não existia ainda ${ }^{1}$.

Estamos buscando discutir a dinâmica me todológica do conhecimento científico e não só ensinando metodologia científica para fins puramente "técnico-científicos". Interessa talvez ventilar modos de entender e fazer ciência e educação do que apenas real çar polêmicas modistas, que alguns especialistas, dizem, já estão "saindo de moda". 0 pós-modernismo, como não poderia deixar de ser, produziu resultados disparatados nesses dois alicerces que estamos introduzindo como tema-problema e que provocaram reações diversificadas, o que talvez de mais negativo tenha sido no sentido da crise de identidade, não aquela que é saber duvidar de si mesmo, aliás, uma das habilidades mais próximas do conhecimento científico. Somenteem ambientes questionadores e civilizados, 0 aluno de qualquer área (seja na graduação ou na pós) pode sentir confiança e absorver a teoria do sujeito, ganhando em parte a cidadania, que segundo Paulo Freire ${ }^{2}$, é uma das principais funções da universidade. Em parte, essa iniciativa é, acreditando que adotando uma postura de estilo dialético, naturalmenteo tom do discurso será crítico, sempre como referência à coerência eà autocrítica ${ }^{1}$.

\section{O conhecimento na contemporaneidade}

O objetivo principal dequalquer plano de ensino é introduzir um trabalho na pós-graduação em que o questionamento crítico seja o critério central da cientificidade, segundo H abermas, quando propõe que somente o questionável pode ser o científico. E também por coerência metodológica, podemos evitar uma certa "filiação", pois um dos objetivos é construir conhecimento por mão própria, não apenas imitar. Outro aspecto é que desejamos relacionar metodologia científica com "o saber pensar", significando, sobretudo, a formação da capacidade de se fazer sujeito com história própria .

As relações de saber e a cultura contemporânea foram mudadas pela subversão da relação com o saber e a verdade através da relação da teoria do sujeito ${ }^{3}$. A omissão desses conhecimentos produz efeitos inevitáveis na formação dealunos que futuramente irão intervir na própria formação do sujeito, ou que no mínimo estarão se relacionando com o ser humano. Com relação 
ao "sujeito", há necessidade de condições complexas e particularmente eventos que para alguns indivíduos não passem de fruto do acaso. $\mathrm{Nem}$ sempre há sujeitado ou sujeito, nem sempre o sujeito não é invariante ou necessário. Ele não é uma consciência, uma experiência, não éa fonte do sentido, mas ele é constituído por uma verdadee não a fonte da verdade. Badiou ${ }^{4}$ define que o sujeito não é tampouco um vazio, um nada, um intervalo. Ele tem consistência, podem-se determinar seus componentes. 0 sujeito não é uma substância, um ser, uma alma, nem uma coisa pensante, porqueeledependedeum processo que começa e acaba, tantas vezes decorrente do ensino, por isso o sujeito não éuma origem. Em particular, não é por haver sujeito que há verdade, mas pelo contrario, porque há verdade, há sujeito. Segundo Badiou 4 , o sujeito é raro, tão raro quanto a verdade. Tanto em Badiou quanto em Foucault ${ }^{3}$, para falar do sujeito, é preciso partir de uma teoria da verdade, pois um sujeito não é outra coisa senão um ponto da verdade ou a dimensão plural local do processo de uma verdade. N essesentido, o processo educacional entra como ponto de partida para verdade por que é o que transmite, 0 que repete, chama-se saber. A atual educação na área de saúde e o seu cientificismo não têm se preocupado com um certo saber filosófico. Ora! Se a verdade éum problema filosófico essencial, ese sua aparição eseu devir não éum juízo, mas um processo real, podemos deduzir, ou melhor, questionar, se a interdisciplinaridade com a filosofia não está sendo omitida do ensino5. A filosofia é o estudo do real. Podemos inferir que a ciência e a educação estão intimamente ligadas a ela e que podem tornar esses futuros profissionais em sujeitos. 0 sujeito é necessário na pós-graduação e não podemos deixar alguns raros alunos se tornarem sujeito ao acaso. Para que uma verdade afirmeeformeum sujeito, deve haver um suplemento, éo quese chama de "evento" ${ }^{\prime \prime}$, que pode ser o processo educacional, o professor ou a ciência como um axioma.

Rumando para aspectos mais abrangentes, a dificuldade de articular a colaboração entre áre as como filosofia, biologia, patologia, literatura, ou seja, a interdisciplinaridade, palavra já tão banalizada no mundo acadêmico e nas diferentes especializações científicas, acabou tornandose o (des)interesse polido, entre estudiosos de campos diferentes, pelo trabalho uns dos outros. Esse aspecto foi analisado por KehInr na conclusão de vários estudos internacionais de áreas diferentes, realizado em agosto de 2002 na Universidade de Stanford (Congresso sobre Interdisci- plinaridade). Desconfiamos que a interdisciplinaridade na pós-graduação está sendo "virtual" (polidez para compensar, por um breve período, a convicção de todos no sentido de que nada que os "outros" possam ter a dizer tem importância real para o trabalho que cada pessoa realiza) e torna-se necessário nossa atuação para que a interdisciplinaridade resulte em projetos de trabaIho conjuntos de potencial inovador. Nesse sentido, as formas dominantes de interdisciplinaridade existentes hoje produzirão, segundo documento do congresso supracitado, na melhor das hipóteses, "conhecimentos novos" que não surpreendem nenhum profissional - emenos ainda patrocinadores e doadores para a pesquisa. 0 que desejamos entre professores e alunos é um estilo de colaboração intelectual que cumpra as promessas que a palavra interdisciplinaridade implica, com um trabalho abarcando diversas disciplinas acadêmicas, cujos efeitos ninguém possa prever e cujos resultados potenciais não poderiam ter sido produzidos isoladamente ${ }^{6}$.

Os cientistas desse encontro, de dezenas de áreas diferentes, trabalhando 24 horas por dia, discutiram o tópico como um conceito de"emergência", mas na verdadeera invenção de um novo formato de trabalho interdisciplinar, não mais conduzido por polidez acadêmica e curiosidade aleatória. Talvez lendo o documento que deu origem a essa discussão, possamos afirmar, para nossa comunidadeacadêmica, que existeum grau excessivo (prático-teórico) de fixação em objetivos que gera a estagnação de qualquer trabal ho intelectual. Ao passo que a capacidade de liberar o controleepermitir o crescentefluxo de pesquisa em curso determina se cada pesquisador será o mais poderoso catalisador da produtividade intelectual $^{6}$.

0 que é o conhecimento e como desejamos organizá-lo? O conhecimento deveocorrer como se fosse uma grande fábrica e nessa organização há lugar para diferentes papeis intelectuais. Com certeza, é preciso haver uma variedade considerável de tais papeis, tanto para administradores, intelectuais e outros membros da pesquisa. No século XIX, a palavra "especialista", "cientista", "perito", "profissional" foi um sinal de que a divisão do trabalho intelectual havia se expandido muito. Em épocas anteriores, o curso universitário básico para todos era constituído de sete artes liberais, que iam de retórica à astronomia. $\mathrm{A}$ especialização acabou triunfando também no século XX e surge um abismo entre as ciências naturais e as humanas, "as famosas duas culturas", seguidas pela separação entre a química ea 
física, a sociologia e a psicologia e assim por diante ${ }^{7}$. Esses superespecialistas, sem intenção, acabaram por causar um desastre que com certeza foi avassalador na dita área biomédica, onde a fragmentação é absolutamente clara.

Todo conhecimento científico se desfigura, ou melhor, se redefine logo que se dissemina na cultura e isso éa essência das representações sociais. Há pelo menos duas causas básicas de existência, ambas de ordem emocional: 0 amor pelo conhecimento e"o medo instintivo do homem de poderes que ele não pode controlar e sua tentativa de poder compensar essa impotência imaginativamente" ${ }^{\prime \prime}$. Daí vemos a importância da representação social na introdução do resultado científico disseminado na coletividade e na cultura. Tanto que, quando a medicina social deseja conhecer uma coletividade para introduzir uma inovação, um dos recursos é a representação social. Uma questão central que tem sido bastante esquecida é a de que o conhecimento científicotecnológico passou a desempenhar um papel decisivo na sociedade, incluindo na economia. Foi Francis Bacon, no século XVII, que formulou a tese da relação fundamental entre saber epoder ${ }^{9}$. $M$ as 0 advento dos tempos modernos não precisou esperar para pôr o conhecimento a serviço do poder. Fala-se muito hoje em dia em sociedade do conhecimento, tema que foi consagrado em um simpósio da UNESCO em dezembro de 2001 em N ápoles. M as a indagação principal ése a sociedade do conhecimento é um fato. É uma ideologia? O u uma utopia? Segundo Rouanet ${ }^{10}$, é um pouco dessas três coisas. Podemos também redefinir se informação e conhecimento são sinônimos, o que implica redefinir a sociedade de conhecimento como sociedade de informação. Efetivamente, vivemos numa sociedade em que somos bombardeados por meras informações que funcionam como sinais, diante dos quais reagimos de modo compatível com o programa que nos condiciona; a informação pura e simplesmente dispensa o trabalho reflexivo que transformaria os conteúdos, devidamente processados pelo nosso aparelho psíquico, em verdadei ro conhecimento ${ }^{11}$. D evemos estar atentos, com relação a fato, ideologia, utopia, se nos cursos de pós-graduação o conhecimento está travestido, bloqueando os alunos para caminhos de uma ação questionadora eficaz, e se de fato esses alunos têm uma ação reflexiva sobre as idéias que lhe são ensinadas ${ }^{10}$.

\section{Condição humana e aprendizado}

O utro aspecto bastante implicante em debates de pós-graduação deveria incluir os diferentes "perigos", os riscos que envolvem a educação e a própria condição humana no mundo das dependências globais, já que o amor pelo conhecimento é uma das causas básicas da existência8 Para isso, Bauman ${ }^{12}$ sugere a metáfora da liquidez para caracterizar o estado da sociedade pósmoderna. Ele questiona a relação de alunos e professores, como indicava Sartre a seus discípulosa terem um projeto, ou seja, uma identidade fixa; mas adverte que, nesse mundo fluido, essetipo de projeto équase suicida. Richard Sennet mostra que o tempo médio de emprego do jovem americano em empresas detecnologia, por exemplo, éde oito meses; quem pode pensar num projeto de vida nessas circunstâncias? Logo, não seria válido questionar a educação, os projetos de pesquisa, os conhecimentos científicos, baseados nessa liquidez, nessa efemeridade? 0 autor argumenta ainda que esses estudantes se movem rapidamente no sentido de urgência, somente pela necessidade de completar dissertações a tempo e assegurar uma próxima promoção . Perguntamosqual a contribuição, nessemundo globalizado, de uma pós-graduação em que uma das condições éformar mestres, equefuturo terá a universidade brasileira e o ensino nos próximos anos? O sistema em que vivemos éde "uma política social de amansamento" e, portanto, de vemos estar atentos ao papel que o ensino desempenha na sociedade do conhecimento, já que a figura do professor é uma peça-chave nas mudanças e "a educação precisa de polêmicos para mudar a sociedade"1. Talvez, em nossas indagações, caibam al guns questionamentos com relação à educação: o magistério é a mais importante das profissões? E o que temos feito para resgatá-lo? O s cursos de pós-graduação estão formando professores ou repetidores?

0 processo de ensino-aprendizagem implica profundas mudanças, então os profissionais se assustam. Por que os profissionais da mudança não mudam nada? Exatamente os transformadores não transformam as coisas, são resistentes. Por que na educação, ferramenta da mudança e transformações, que a pedagogia aborda, encontramos educadores tão resistentes às mudanças? Ocorre que há grandes projetos de mudança nas universidades, desdeque elas fiquem defora ${ }^{1}$. Há uma discussão filosófica, epistemológica muito interessante, sobre o que se chama de contradição performática em lógica, ou seja, um discurso 
que nega o próprio discurso. É o caso do avaliador que não quer ser avaliado, o questionador que não quer ser questionado; há também a ambiguidade do poder. 0 poder também parecenão estar interessado em mudar, o sistema prefereuma política social de domesticação'.

Uma maneira de domesticar o professor é maltratando-0, por exemplo, pagando-o mal, formando-o mal. Fala-se também, por outro lado, de um sistema pedagógico pouco móvel, muito autodefensivo, talvez corporativo ${ }^{1}$. A importância da educação está em levar o indivíduo a saber pensar e não tem nada a ver com pessoa politiqueira, mas com propósito de formar um sujeito capaz de formar a própria história².

0 instrucionismo, uma proposta que vem de fora para dentro e de cima para baixo e que conserva o aluno como objeto, não chegando a ser sujeito de seu conhecimento, é algo muito preocupante para os educadores. De um lado, há o mundo da educação, da emancipação e da autonomia. De outro, o mundo do ensino, que tem intrinsecamente um efeito imbecilizante de reproduzir a ignorância ${ }^{1}$. Isto vem a corroborar o que foi dito, em outras palavras, que o centro da aprendizagem é saber reconstruir, elaborar e questionar. Talvez a aula não seja o centro, mas um instrumento importante. 0 centro da aprendizagem éo professor e o aluno. Podemos ainda acrescentar que, segundo grandes educadores, ao invés do construtivismo, o reconstrutivismo seria uma nova construção do conhecimento, que na verdade nós reconstruímos a partir do que já existe ejá se sabe. 0 construtivismo éum paradigma. Precisamos pensar também que a habilidade de renovar os conteúdos, renovando os métodos, é o equilíbrio das duas coisas: saber pensar e saber intervir. Há uma dissonância entre saber pensar e intervir. Demo ${ }^{1}$ insiste em dizer que grande parte desse trabalho tem de ser focado no professor. Nessa linha, se você não resgata o professor, não resgata a educação. Se o professor não éum incluído, como ele podeajudar a promover a inclusão? Na prática, o questionamento pedagógico é o seguinte: não é possível só ministrar aula. Deve-se orientar, avaliar, levar a elaborar. Ainda segundo Demo", "uma sociedade onde o professor é mal tratado, obviamente é uma sociedade indigna, que não quer se desenvolver". N ós ainda acrescentaríamos, nos dizeres de Paulo Freire ${ }^{2}$, que a escola é o lugar para o professor ser feliz. A educação pública de qualidade numa universidade ainda éuma política para levar o país a um projeto de uma sociedade própria. Muitos consideram que a década de noventa foi perdida na educação. Para Gadottti ${ }^{13}$, apenas al guns países democráticos, onde se criou uma concepção concreta de educação para a cidadania, constituem-se exemplos de sucesso na educação. Essa teoria ainda é fundada nos princípios de Paulo Freire e, atualmente, Gadotti ainda dirige o Instituto Paulo Freire na USP. Gadotti ${ }^{13}$ insiste que o sistema educacional no Brasil tem uma avaliação que pode ser válida, mas as causas não são avaliadas. Embora banalizada, a palavra cidadania caracteriza-se pela democratização da educação em termos de acesso e permanência e pela participação na gestão e escolha democrática dos dirigentes educacionais. Um movimento nesse sentido foi iniciado só na década de oitenta e precisa ser reavaliado agora. Uma definição de cidadania para Paulo Freire é que a formação da escola cidadã é aquela que se assume como um centro de direitos e deveres, que viabiliza a cidadania de quem está nela e de quem vai a ela. Paulo Freireacredita quea escola écidadã, na medida em todos que usam seu espaço exercitam a construção de cidadania. É uma escola coerente com seu discurso formador e libertador.

Outro aspecto da educação e pedagogia éque se deve reformular questões, por exemplo, se a avaliação desampara o professor, por se tirar dele recursos como prova e reprovação, nos quais ele sempreseapoiou? Essa pergunta tem muitas vertentes, ela é de cunho mais disciplinar do que educativo. A questão está na formação do educador, não só acadêmica, mas a formação ao longo da vida, como sinaliza o relatório da UNESCO para a educação do século XXI. A avaliação é a prática subsidiária da construção de resultados satisfatórios: notas e/ou conceitos são modos sintéticos de registrar a qualidade desses resultados. H istoricamente, esses elementosse confundem na mente de educadores e educandos, assim como de administradores educacionais ${ }^{13}$. Interessante que Luckesi, como historiador da avaliação da aprendizagem desde 1968, e professor da pós-graduação da Universidade Federal da Bahia, relata que flagrou nas práticas dos jesuítas do século XVI características parecidas com as que os professores atualmente imprimem em suas relações com os alunos ${ }^{13}$. 0 novo paradigma denota uma evolução e uma incorporação de uma utopia e acrescenta que a pedagogia também precisa ser resgatada. Tudo isso num certo sentido se perdeu num local amargo no qual a escola se tornou. Na verdade, a pedagogia une todas as ciências e os educadores têm que resgatar esse seu grande sentido de formar, de 
conduzir pessoas e de encantar, pois a universidade hoje vive em meio a muita desesperança ${ }^{13}$. A felicidade na escola não é uma questão de opção metodológica ou ideológica. É uma obrigação essencial dela.

\section{Pesquisa}

O significado da palavra "pesquisa" não parece ser muito claro ou, pelo menos, não éunívoco, já que, desde o presidente da General M otors até os membros da Phi Delta Kappa Fraternity, tentaram defini-la. Anos atrás (em 1929), foram propostas quatro definições da palavra "pesquisa" para que vários estudiosos escolhessem uma delas. 0 resultado foi que as quatro definições tiveram votose, inclusive, houve quem considerasse o conceito de pesquisa como indefinível ${ }^{14}$.

0 que leva o homem a investigar? Einstein disse, certa vez, que a ciência consiste em criar teorias: "I deamos uma teoria após outra", - disse - "e o fazemos porque nos deleitamos compreendendo". A compreensão, para Einstein, se alcança quando reduzimos "os fenômenos, por um processo lógico, a algo já conhecido ou (na aparência) evidente" ${ }^{14}$. 0 valor essencial da investigação científica reside no fato dequesatisfaz nossa curiosidade, ao realizar nosso desejo de conhecer, enos remete ao queA ristóteles já havia escrito: "[...] Aprender é o maior dos prazeres, não só para o filósofo, mas também para o resto da humanidade, por pequena que seja sua capacidade para isso $[\ldots]^{\prime \prime 14}$.

Rodolfo Mondolfo afirma que a pesquisa surge quando se tem consciência de um problema e nos sentimos impelidos a buscar sua solução. A indagação realizada para alcançar essa solução constitui, precisamente, a pesquisa ${ }^{14}$. 0 ponto de partida da pesquisa é, pois, a existência de um problema que se deverá definir, examinar, avaliar e analisar criticamente para, em seguida, ser tentada sua solução. 0 primeiro passo será, então, delimitar o objeto da investigação - o problema - dentro dos temas possíveis. Platão, em seu diál ogo M enon, estabeleceu-o com meridiana claridade: E como buscarás, ó Sócrates, aquilo que ignoras totalmente? $\mathrm{E}$ das coisas que ignoras, qual te proporás a investigar? E se porventura chegaresa encontrá-la, como te advertirás que essa é a que conheces? - Entendo o que queres dizer, $M$ enon [...] Q ueres dizer que ninguém pode indagar aquilo que sabe, nem o quenão sabe; porquenão investigaria 0 que sabe, pois já o sabe; nem o que não sabe, pois nem ao menos saberia o que deve investigar ${ }^{14}$.
Precisamos aumentar o espaço para os alunos, para eles avançarem em seis itens básicos para os critérios formais da demarcação científica. Esses critérios devem ser muito bem debatidos pelo corpo docente para que 0 aluno aprenda a ter um discurso reconhecidamente científico. Para tal, precisa ter coerência, sistematicidade, consistência, originalidade, objetivação, discutibilidade para chegar à formalização ${ }^{1}$.

Para que uma teoria seja considerada válida, não basta a lógica, a si stematização. Precisa ainda ser "aceita". Antes de mais nada seria relevante destacarmoso início de tudo: a importância fundamental do conhecimento e do papel orientando/orientador nas teses e dissertações. Para discutirmosesse importantee delicado assunto, uma proposta de um tema seria debater o que os autoreshoje denominam intersubjetividade, lembrando que a própria expressão "defesa de tese" trai seu fundo de pano político, insinuando que pode não só ser contestada por questões formais, mas igualmente políticas ${ }^{1}$. É necessário introduzir na pós-graduação a dinâmica do questionamento desconstrutivo, reconhecendo um aluno com autocrítica. E possibilitando a esteum ambiente favorável ao desenvolvimento de elaboração própria, de modo que ele consiga efetivamente sua emancipação.

$\mathrm{N}$ ão podemos deixar de pensar profundamente sobre a pesquisa qualitativa em saúde, tal como define $M$ inayo ${ }^{15}$, especialista em pesquisa qualitativa na área de saúde: A saúde enquanto questão humana e existencial é uma problemática compartilhada indistintamente por todos os segmentos sociais. Porém, as condições de trabalho qualificam de forma diferenciada a maneira pela qual as classes e seus segmentos pensam, sentem e agem a respeito dela. Isso implica que, para todos os grupos, ainda que de forma específica e peculiar, a saúde e a doença envolvem uma complexa interação entre os aspectos físicos, psicológicos, sociais e ambientais da condição humana ede atribuição de significados. Poisa saúdeea doença exprimem agora esempreuma relação queperpassa o corpo individual e social, confrontando com as turbulências do ser humano enquanto ser total. N esse sentido a pesquisa qualitativa entra como objeto princi pal de discussão, e entendida como aquelas capazes de incorporar a questão do significado e da Intencionalidade como inerentes aos atos, às relações e às estruturas sociais, sendo essas últimas tomadas tanto no seu advento quanto na sua transformação, como construções humanas significativas. 


\section{Educação na área da saúde}

Questões como políticas de saúde devem ser exaustivamente debatidas tanto quanto políticas de ensino, e dentro deste debate o perfil dos profissionais naárea de saúde. Além da vocação (que é imprescindível), é necessário instituir políticas de recursos humanos e principalmente os responsáveis pela educação médica, que estão inseridos numa complexidade e têm que estar dispostos a investir em grandes mudanças, incluindo a questão curricular. Essequestionamento deve ser feito perguntando-se, primeiramente, como tornar realidade esse tipo de educação médica, que tem um direcionamento à atenção primária, buscando uma linha de pesquisa voltada para prevenção e com ensinamentos metodológicos perfeitamente qualificados para a chamada pesquisa qualitativa. Segundo, que há uma série de outros atributos em relação ao perfil discente, onde esses tenham sensibilidade, um compromisso ético e político com a cidadania. Dentre tantos debates sobre política de saúde, perguntamos: há possibilidade de eliminar a "restrição técnica" dos profissionais da área de saúde? Esses, sempre desinteressados em política de saúde e a verdadeira práxis dela pela inclusão de disciplinas didáticas nos cursos de pós-graduação e pela sistematização das atividades didáticas empreendidas durante os treinamentos para elaboração de teses e dissertações. Ou esse êxito de pende de um investimento na mudança da educação médica durante o período da graduação?

A ética aprendidanauniversidadeéoutro ponto nevrálgico para a educação médica. Podemos contar hoje com uma bioética? Seria o que os alemães chamam deética com hífen (bio-ética). Zizek ${ }^{16}$ fala que o problema não é que a ética universal seja dissolvida numa miríadedetemas particulares (bioética, ética comercial, éticamédica, etc.) , masmuito pelo contrário, quedeterminadosavanços científicos se confrontam com valores humanistas, ameaçando nosso senso de dignidade e autonomia. Autores como Heidegger já viam como um "perigo" inerenteà tecnologia modernaa biogenética: "A natureza humana, éassim 'desubstancializada', privada de sua impenetrável densidade, daquilo que ele chamou de 'terra'". Segundo Francis Fukuyama, a própria humanidade depende de certa noção de uma natureza humana herdada, da dimensão impenetrável em/de nós mesmos na qual nascemos/ somosatirados: o homem só existena medida em que existea impenetrável natureza inumana. Slavoj comenta que o "preço que pagamos por essa solução éa separação fetichista entre ciência eética" ${ }^{16}$.
Zizek $^{17}$ afirma que, ao contrário da ideia de que a curiosidade éinata aos seres humanos, ela é construída. 0 ser humano vai adquirindo esse desejo de conhecer, dependendo do ambienteem que estuda, trabalha, vive. 0 mesmo se dá na pós-graduação. Citando Jacques Lacan, afirma que a atitude espontânea dos ser humano é a de "não quero saber disso, o desejo fundamental é o do não saber muito". Todo verdadeiro progresso no conhecimento deve ser adquirido por meio de uma dolorosa luta contra nossas propensões espontâneas. Esse modo de ver sobre a cultura eo conhecimento, em Lacan eZizek, dão um formato ao avesso do ser humano e bem paradoxal ao que se tem dito sobre o desejo de conhecer.

Presenciamosqueo vínculo definanciamento distorce o trabal ho de pesquisa. À medida que foram aumentando os vínculos entre interesses comerciais e atividade acadêmica, a chamada pesquisa desinteressada diminuiu em toda gama deatividade científica. A pesar disso, os cientistas deum modo geral continuam não levando muito a sério a idéia dequevínculos de financiamento podem distorcer seu trabalho. John Ziman, membro da Royal Society (Reino Unido), um grande estudioso de sistemas sociais da ciência, escreveu recentementeque, na universidademoderna, a pesquisa desinteressada deixou de ser viável ou necessária para proteger a objetividade científica ${ }^{18}$. Podemos discutir: a pesquisa desinteressada deixou deser viável? Alguns periódicos científicos se recusam a publicar artigos de revisão escritos por autores que possuem vínculos financeiros com seu tema. 0 papel daqueles que produzem conhecimento científico deve ser separado daqueles que podem se beneficiar financeiramente desse conhecimento. Qualquer coisa fora disso, com o tempo, acarreta o declínio irreparável da confiança que o público deposita na ciência e na medicina ${ }^{18}$. Pensando nesse sentido, devemos debater com toda academia se o financiamento de todas as pesquisas é um dever do Estado. E mais, qual a situação dos fomentos de pesquisa do governo, que muitas vezes deixam de cumprir com seus deveres, eainda, qual a responsabilidade dos dirigentes da universidade. Alguns são a favor de que o trabalho da ciência dependa do apoio público sim, pois há muito tempo passamos do ponto em que experimentos científicos podiam ser financiados por al guns cientistas ricos e hoje dependemos muito do apoio do governo ${ }^{18}$.

Poderíamos ponderar também quanto ao destino final das pesquisas em relação à publica- 
ção. Essa política no Brasil modificou-se radicalmentepara os cursos de pós-graduação. Do ponto de vista internacional, essa política foge ao nosso controle, com uma enormetendência dessas grandes revistas internacionais privilegiarem alguns centros de pesquisa de alta confiabilidade. Esse critério de seleção para publicação tornou-se angustiante para o pesquisador, ou seja, as pesquisas brasileiras, no caminhar dessa estrada, deverão ser muito melhores que as outras (internacionais) para serem aceitas? É evidente que somente com pesquisas de qualidade teremos acesso às pesquisas internacionais, porém não se trata só disso. Qual o caminho do "mercado" de publicação para as pesquisas de qualidade? Quais os critérios adotados para classificar essa qualidade? Outro fato angustiante para o pesquisador é a produção científica massificante. Então um questionamento importanteéo quequeremos na pósgraduação: na ciência en quanto criação, poderáo pesquisador produzir sem inspiração, sem a paixão? A criação na ciência não é distinta da do artista. Sobretudo, sem apoio técnico, financeiro, muitas vezes sem o reconhecimento da universidade. Com isso tudo, perde-se a motivação.

Finalmente, devemos levantar discussões técnicas propriamente ditas com relação à elaboração das teses e dissertações, e não começar por elas, como o núcleo central das teses. Lembrando que as teses são, sobretudo, ritos de passagem, geralmente predominando o lado ritualista sobre a criatividade. 0 orientador tem um papel fundamental no andamento desse trabalho. Um ponto que pode ser trabalhado é que, se o orientador pertencea instituição, eletambém zela pelo paradigma vigente? Isso interfere na aprovação final para o seu orientado'?

A pós todas as discussões, 0 aluno passa a delimitar o objeto de sua pesquisa; poderíamos então desenhar bem na pós-graduação o problema e o tema para que o aluno tenha clareza, desenvoltura, evitar modismos. A boa medida do tema relevância e problema a ser questionado éo centro da tese e dissertação. Isso deve ser muito bem discutido na pós-graduação, pois o "problema" versus "tema" não pode estar acima da capacidade e do entusiasmo de cada profissional. Os orienteadores devem estar atentos, pois o "proble- ma" a ser questinonado nas dissertações deve estar à altura da capacidade criativa do aluno e de tudo que Ihe foi oferecido durante o curso.

\section{Consideraçõesfinais}

Na pós-graduação, os alunos devem ser direcionados a inovar, explorar e enfrentar a futura conclusão do trabalho, elaborando bem as hipóteses, delimitando-as às linhas de pesquisa estabelecidas.

Essa pós-graduação deve saber construir o chão, manejando conceitos-chave para a desenvoltura do aluno em relação à teoria. Não se trata, apenas, de percorrer autores (revisão de literatura), no sentido de repetir o que outros autores já criaram. Com relação às variáveis, a lógica da análise do levantamento de dados apresenta uma exaustiva descrição dos significados diferentes que, no sentido formal, a relação entre duas variáveis pode ser assumida indicando as formas de relação simétrica, relação recíproca erelação assimétrica. Os conceitos e diferenciação de variável estão bem circunstanciados, bem como os fatores determinantes? Tem sido uma normativa 0 teste de controle? 0 significado das relações entre variáveis tem sido bem discutido? A amostragem tem sido bem ponderada e analisada?

Tantos outros tópicos poderíamos questionar se conhecêssemos melhor a pós-graduação a qual estamos inseridos ou aquela na qual deveríamos verdadeiramente nos sentir inseridos. Provisoriamente, interrompemos esses questionamentos com uma frase de Demo $0^{1}$ : Ao mesmo tempo, com relação à universidade, qualquer olhar mais crítico reconhece que somos "ricos" e sabidos mas igualmente mais infelizes. Primeiro, porque somos mais ricos e sabi dos apenas no topo da pirâmide social da instituição. Segundo, porque o conhecimento tem tomado o rumo exclusivo da competitividade. Não é possível ser feliz, nem sendo colonizado, nem colonizando os outros. Com isso estamos apenas preparando o confronto, isso também deve ser lembrado na reclamação de Brecht: Se o conhecimento não nos torna mais felizes, não pode ser científico. 


\section{Colaboradores}

FM Namen eJ Galan Jr. participaram igualmente de todas as etapas da elaboração do artigo.

\section{Referências}

1. Demo P. A metodologia do conhecimento científico. São Paulo: Atlas; 2000.

2. Freire P. Conscientização: teoria e prática da libertação. 3a ed. São Paulo: Moraes; 1980.

3. Foucault M. Problematização do sujeito: psicologia, psiquiatria e psicanálise. Rio de Janeiro: Forense Universitária; 1999.

4. Badiou A. Para uma nova teoria do sujeito: conferências brasileiras. Rio de Janeiro: Relume Dumará; 1994.

5. Rosset C. 0 princípio da crueldade. Rio de Janeiro: Rocco; 2002.

6. Ciência Nova. Folha de São Paulo 2002; 24 nov. p. 48.

7. 0 paraíso perdido do conhecimento. Folha de São Paulo 2003; 11 mai. p. 3.

8. Moscovici S. A representação social da psicanálise. Rio de Janeiro: Zahar; 1978.

9. Lakatos EM, Marconi MA. M etodologia científica. 3a ed. São Paulo: Atlas; 2000.

10. Fato, ideologia, utopia. Folha de São Paulo 2002; 24 mar. p. 14-15.

11. Kutz R. O efeito colateral da educação fantasma. Folha de São Paulo 2004; 11 abr. p. 18-19.

12. Bauman Z. M odernidade e ambivalência. Rio de Janeiro: Zahar; 1999.

13. Gadotti M. Escola cidadã, uma utopia virando realidade. Jornal do Brasil 2000; 4 jun. p. 1-2.

14. Asti Vera A. A metodologia da pesquisa científica. Porto Alegre: Globo; 1983.

15. M inayo MCS. 0 desafio do conhecimento: pesquisa qualitativa em saúde. 7ạ ed. Rio de Janeiro: Abrasco; 2000.

16. Zizek S. A falha da bio-ética. Folha de São Paulo 2003; 22 jun. p. 4-8.

17. O melodrama do conhecimento. Folha de São Paulo 2002; 20 jan. p. 13.

18. Zizek $\mathrm{S}$. Conflito de interesses na universidade pósacadêmica. Folha de São Paulo 2003; 28 set. p. 16-17.

Artigo apresentado em 25/08/2008

Aprovado em 08/10/2008

Versão final apresentada em 19/11/2009 